\section{A comparison of olfactory adaptation among seven odorants and their relationship with several physicochemical properties*}

\author{
HERBERT STONE†, GORDON T. PRYOR, and GERALD STEINMETZ \\ Life Sciences Division, Stanford Research Institute \\ Menlo Park, California 94025
}

A study was made comparing olfactory sensitivity before and after 100 sec of adaptation for stimuli representing several odorant classes with varying physicochemical properties. Measures taken were absolute detection thresholds and magnitude estimates of suprathreshold stimuli. Significant rank-order correlation coefficients $(<.90)$ were found between nonadapted and adapted absolute detection thresholds, vapor pressure, and percent adaptation.

For a complete understanding of olfaction, it would seem essential to know the properties of the stimuli that are related to the various sensory-perceptual phenomena. However, unlike the physical properties of intensity and frequency for light and sound, no such obvious, simple dimensions of olfactory stimuli are known. Odorous molecules differ in terms of many physicochemical properties, none of which provide easily defined continua. On the other hand, it may be possible, as in biochemical pharmacology, to relate various perceptual phenomena of odors to certain limited sets of properties and thus gain some insight into the receptor mechanisms involved. Several investigators have had some success in this regard. Amoore (1970) has theorized that odor quality can be predicted through examination of the stereochemical features of the molecule. For some odorants, Amoore (1970) demonstrated a highly significant relationship between odor quality and molecular size and shape. Theimer and Davies (1967) and Davies (1970) claimed that odor quality was determined through its physical properties, i.e., rate of desorption, molecular cross-sectional area, and ratio of length to breadth of molecule. Döving (1970) found statistically significant correlation coefficients $(>.90)$ between neurophysiological responses produced by a homologous series of alcohols and several physicochemical parameters: hydrogen binding, cross-section, adsorption

*This research was supported by Grant NBO7832 from the National Institute of Neurological Sciences of the National Institutes of Health. The authors thank the panel members for theix cooperation.

tAddress reprint requests/correspondence to: Herbert Stone, Life Sciences Division, Stanford Research Institute, Menlo Park, California 94025. energy, molecular weight, polar factor, adsorption energy, and adsorption coefficient. It is likely that some of these physicochemical parameters are indirect measures of each other and that only through systematic investigation with more odorants will it be possible to identify those that are most important.

An aspect of olfactory perception that has received only limited investigation behaviorally and in terms of stimulus properties is adaptation-the loss of sensitivity that accompanies continuous exposure to an odorant. Although the general characteristics of olfactory adaptation have been deseribed (Moncrieff, 1957; Steinmetz et al, 1970; Pryor et al, 1970), too few classes of odorants have been examined under comparable conditions to provide clues as to any physicochemical properties of the stimulus that might be related to this phenomenon. The purpose of the present study was to begin to remedy this situation by comparing olfactory adaptation of representatives from several classes of odorants having different physicochemical properties. The odorants were three aliphatic alcohols (propanol, pentanol, and hexanol), three saturated cyclical compounds (cyclohexane, cyclohexanone, and cyclooctane), and an ester (n-hexyl acetate). They represented four of Amoore's (personal communication, 1972) odor quality classifications. Water solubility ranged from infinity to insoluble, and vapor pressure (at $23^{\circ} \mathrm{C}$ ) ranged from 3.1 to $88 \mathrm{~mm} \mathrm{Hg}$. Thus, a fairly wide range of two physicochemical properties and one perceptual scheme were represented.

\section{METHODS \\ Subjects}

The six Ss, two male and four of experienced Ss on the basis of female, were drawn from a larger pool availability and absence of gross olfactory abnormalities. Not all Ss participated in all experiments; the values given are usually for three, but not more than five, Ss.

\section{Test Odorants}

The odorants used were propyl alcohol, pentyl alcohol, hexyl alcohol, cyclohexane, cyclohexanone, cyclooctane, and hexyl acetate. All compounds were redistilled before use. Purity, checked by gas chromatographic analysis, was greater than $99 \%$.

\section{Apparatus}

An olfactometer was used to present the stimuli (Stone et al, 1969). In brief, it is an air dilution system that permits delivery of a known concentration of an odorant for a controlled duration. It includes electronic timers and solenoid valves to facilitate ease of odor presentation and to select odor intensities and test intervals rapidly and accurately. Two channels were used to present the stimuli: one supplied the adapting stimulus and the other was used to present test stimuli. Both entered the main airstream just before its outlet to $S$. Communication between $E$ and $S$ during testing was by a visual system of light signals and by $S$ 's vocal report of magnitude estimation.

Concentrations of the stimuli were calculated from vapor pressure, experimental temperature, and gas-flow rates, according to previously established procedures (Stone et al, 1962).

Experimental Design and Analysis

The absolute detection threshold $\left(I_{t_{0}}\right)$ was determined for each $\mathbf{S}$ prior to the adaptation experiment and was verified at the beginning of each test session, using a tracking procedure described earlier (Steinmetz et al, 1969). Briefly, this procedure involved presentation of test stimuli randomly interspersed with blank stimuli. The first few test stimuli were easily detected, and the test concentration was decreased in a stepwise manner until test stimuli were no longer detected. The subsequent test and blank samples were presented in a random sequence until a threshold was established.

A scale of subjective intensity for the odorant was then established for each $S$, using the method of magnitude estimation (Pryor et al, 1970). These scales were verified at the conclusion of the experiment. At the onset of the adapting stimulus, which was $10 \times I_{t_{o}}$, $S$ was asked to give an estimate of its magnitude; a second magnitude estimate was obtained during the last 5 sec of adaptation. The adapting 


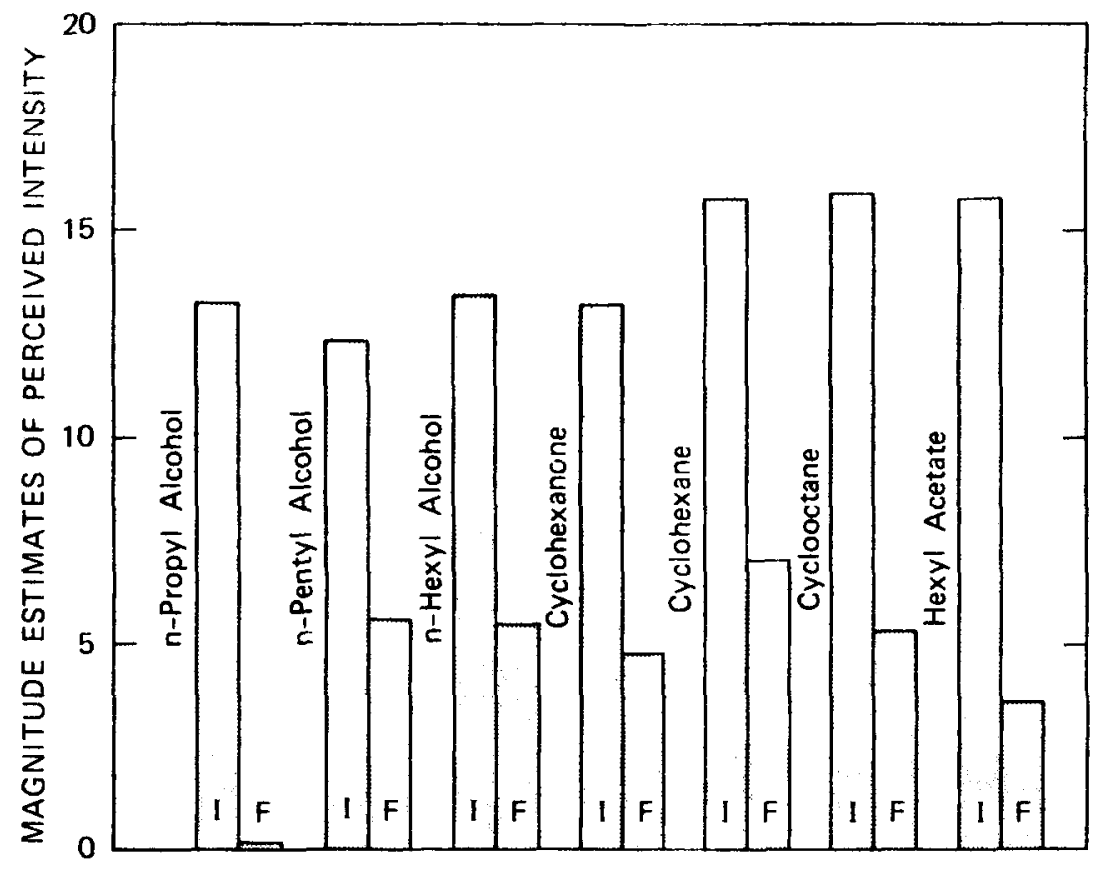

Fig. 1. Geometric means of the magnitude estimates of perceived intensity for the seven odorants at a concentration of $10 \times I_{t_{0}}$ before (I) and after (F) adaptation for $100 \mathrm{sec}$ of continuous stimulation. The entries on the $x$-axis are the pooled results of three to four Ss for each odorant.

stimulus was then terminated after $100 \mathrm{sec}$ of continuous stimulation, coincidental with the presentation of a test stimulus to estimate the change in threshold $\left(I_{t}\right)$ or some multiple of $I_{t_{o}}$ $\left(5,10,15,20\right.$, or $\left.30 \times I_{t_{o}}\right)$ to estimate the change in intensity of suprathreshold stimuli. Each of these latter measurements required about 2 sec. At least 20 sessions were held for each $\mathbf{S}$ for each odorant.

\section{RESULTS}

Figure 1 shows the average magnitude estimates obtained at the onset and during the last 5 sec of adaptation for the seven odorants. Since test stimulus concentrations for each $\mathrm{S}$ for each odorant were multiples of $I_{t_{0}}$, comparisons among odorants in this way seems justified. No appreciable differences among the seven odorants in the perceived intensity of stimuli at a concentration of $10 \times I_{t_{0}}$ were apparent except for n-propyl alcohol, which showed adaptation below threshold. For the remaining six odorants, Ss experienced between $50 \%$ and $75 \%$ adaptation within the 100 -sec test interval.

Figure 2 shows the psychophysical functions of perceived intensity for the nonadapted and adapted conditions for the seven odorants. Before adaptation, the exponents ranged from 0.63 to 0.82 . At the conclusion of the adaptation period, the exponents increased for all odorants except pentyl alcohol, which did not change appreciably.

Absolute detection thresholds before and after adaptation are shown in Table 1, along with selected physicochemical properties.

The rank-order correlation between nonadapted and adapted $I_{t}$ among odorants was $0.95(\mathrm{p}<.01)$. Both values were related to vapor pressure (nonadapted $r=0.95, p<.01$, adapted $r=0.9, p<.01)$. The rank-order correlation between percent adaptation and vapor pressure was 0.48 (n.s.). However, if cyclohexane is excluded, this index of relationship was 0.96 ( $p<.01)$. No other relations among these selected psychophysical and physicochemical properties were evident.

\section{DISCUSSION}

The results of this experiment provide an initial comparative basis for relating physicochemical properties of several representative odorants to several aspects of olfactory sensitivity and adaptation. An obvious relationship between absolute detection thresholds and vapor the only physicochemical property that appeared to be related to adaptation, although only when cyclohexane was excluded. Cyclohexane had an exceedingly high $I_{t}$ compared with the other six odorants. It is possible that this may pressure was apparent. This was also be related to its anomalous behavior during adaptation with respect to vapor pressure.

Two of the odorants used-propyl and pentyl alcohols-were also used by Cain and Engen (1969) in their adaptation experiments, although the mode of adaptation was not similar. In their studies, $\mathbf{S}$ exposure to a stimulus was based on number of breaths. The exponents for the functions in the nonadapted condition were in good agreement in the two studies: for n-propyl alcohol, the exponent was 0.69 vs 0.69 ; for $n$-pentyl alcohol, the exponent was 0.75 vs 0.56 .

Cain and Engen (1969) and Pryor et al (1970) found that the exponent of the psychophysical function increased after adaptation. In the present experiment, the exponents for six of the seven odorants also increased. Pentyl alcohol was the only exception, with no apparent change being noted. This odorant also showed the least increase in threshold after adaptation. These changes were consistent with a previous suggestion (Pryor et al, 1970) that a longer adaptation time or higher adapting concentration would be necessary to achieve the same percentage of decrement in the perceived magnitude of a strong stimulus than in the magnitude of a weak stimulus. Since the $I_{t}$ is also increasing during the adaptation period, the effective range of perceived intensity is also decreasing. Therefore, for a particular stimulus in which there was a large change in threshold, one would also expect a large increase in the exponent. In fact, the rank-order correlation between percent increase in $I_{t}$ and the change in exponents was $0.82(p<.05)$.

A comparison of the data reported in Table 1 with Amoore's (1970; personal communication, 1972) classification system showed no differences as a function of odor quality.

Davies (1970) and Theimer and Davies (1967) proposed that molecular size, geometry, and desorption rates were important determinants of odor type. They reported a strong relationship between rate of desorption and perceived intensity of a series of musk odorants. If we consider vapor pressure as being associated with the rate at which odorants penetrate the mucosa (i.e., are adsorbed and subsequently are desorbed), then the comparison of vapor pressure with detection thresholds and amount of adaptation was reasonable. We observed good agreement and relatively high correlation $(>.90)$ between detection thresholds, vapor pressure, and percent adaptation (excluding cyclohexane). These results 


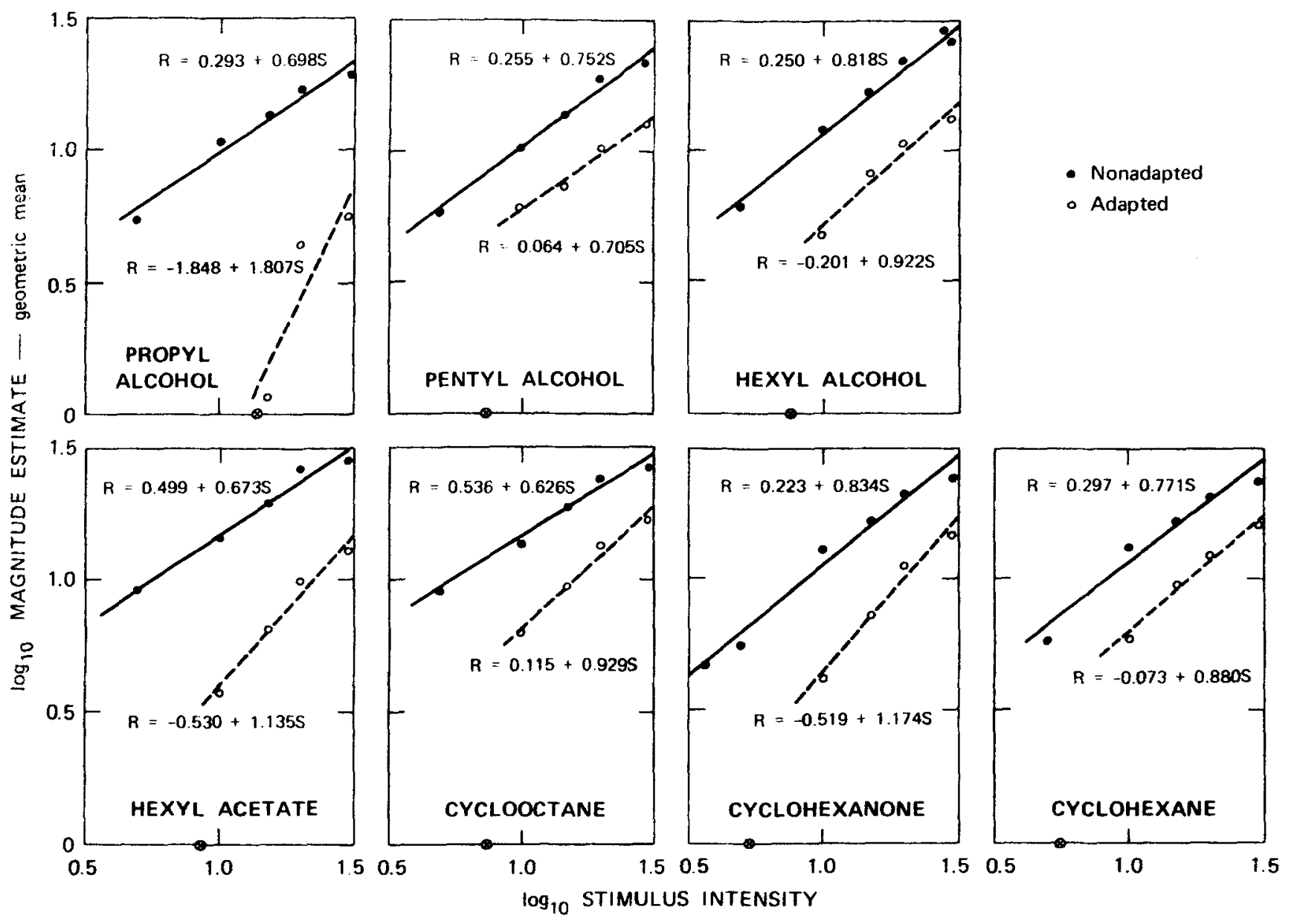

Fig. 2. Equations of the lines for the nonadapted and adapted conditions for the seven odorants: the individual detection thresholds after adaptation are noted on the $x$-axis.

Table 1

Detection Thresholds, Psychophysical Functions in Nonadapted and Adapted Conditions, and Selected Physicochemical Properties

\begin{tabular}{|c|c|c|c|c|c|c|c|c|}
\hline \multirow[b]{2}{*}{ Stimulust, +} & \multicolumn{2}{|c|}{$\begin{array}{c}\mathbf{L}_{t}{ }^{*} \\
0^{-6} \mathrm{~g} / 1\end{array}$} & \multirow{2}{*}{$\begin{array}{c}\text { Percent } \\
\text { of Adapta- } \\
\text { tion** }\end{array}$} & \multicolumn{2}{|c|}{$\begin{array}{c}\begin{array}{c}\text { Psychophysical } \\
\text { Function }\end{array} \\
\end{array}$} & \multirow{2}{*}{$\begin{array}{l}\text { Molec- } \\
\text { ular } \\
\text { Weight }\end{array}$} & \multirow{2}{*}{$\begin{array}{c}\text { Water } \\
\text { Soluble } \\
\text { g/100 ml } \\
\end{array}$} & \multirow{2}{*}{$\begin{array}{l}\text { Vapor } \\
\text { Pressure } \\
\text { mm } \mathrm{Hg}_{\mathrm{g}} \\
\text { at } 23^{\circ} \mathrm{C}\end{array}$} \\
\hline & $\begin{array}{c}\text { Non- } \\
\text { adapted }\end{array}$ & Adapted & & $\begin{array}{c}\text { Non- } \\
\text { adapted }\end{array}$ & Adapted & & & \\
\hline $\begin{array}{l}\text { Propyl alcohol }{ }^{E} \\
\text { Pentyl alcohol } \\
\text { Hexyl alcohol } \\
\text { Cyclohexane } \\
\text { Cyclooctane } \\
\text { Cyclohexanone } \\
\text { Hexyl acetate }^{\mathrm{F}} \\
\text { Methyl isobutyl ketone }\end{array}$ & \begin{tabular}{r|}
2.8 \\
1.2 \\
1.5 \\
35.6 \\
3.6 \\
1.6 \\
2.3 \\
9.7
\end{tabular} & $\begin{array}{r}38.6 \\
8.5 \\
10.9 \\
202.9 \\
26.4 \\
10.9 \\
19.2 \\
38.8\end{array}$ & $\begin{array}{c}\text { 100.0\% } \\
\mathbf{5 3 . 9} \\
\mathbf{5 8 . 3} \\
\mathbf{5 4 . 9} \\
67.2 \\
63.2 \\
\mathbf{7 6 . 8} \\
\mathbf{8 5 . 0}\end{array}$ & $\begin{array}{l}0.69 \\
0.75 \\
0.82 \\
0.77 \\
0.63 \\
0.83 \\
0.67 \\
1.08\end{array}$ & $\begin{array}{l}1.85 \\
0.71 \\
0.92 \\
0.88 \\
0.93 \\
1.17 \\
1.14\end{array}$ & $\begin{array}{r}60.09 \\
88.15 \\
102.17 \\
84.16 \\
112.20 \\
98.14 \\
144.21 \\
100.16\end{array}$ & $\begin{array}{l}\infty \\
2.7 \\
0.59 \\
\text { Insol. } \\
\text { Insol. } \\
2.4 \\
\text { Insol. } \\
1.9\end{array}$ & \begin{tabular}{r|}
21.3 \\
3.1 \\
4.7 \\
88.0 \\
8.9 \\
6.6 \\
5.9 \\
41.3
\end{tabular} \\
\hline
\end{tabular}

*Detection thresholds.

**Percent adaptation measured as difference in perceived intensity after 100 sec stimulation at $10 \times I_{t_{0}}$.

$+C, E, F$, and $P$ refer to four of the Amoore classifications: Camphoraceous, Ethereal, Floral, and Peppermint.

t+Results for methyl isobutyl ketone from previous experiments (Steinmetz et al, 1969; note that previous threshold was incorrect by 10 due to error in transposing).

are consistent with the work of Jones (1955), who found a high correlation $(\mathrm{r}=.91)$ between odor threshold and vapor pressure.

These results are also consistent with the work of Laffort (1968), who proposed that the air:mucus (or air:water) partition coefficient was an important determinant of odor type and odor threshold. We suggest that the air:mucus partition coefficient and the rate at which odorant molecules penetrate the mucus (are adsorbed, then desorbed) are also related (directly or indirectly) to vapor pressure. Although vapor pressure was found to be the one physicochemical parameter significantly correlated with 
the perceptual measures, it does not necessarily follow that vapor pressure is applicable in a general sense. Davies (1970), Döving (1970), and Laffort (1968) have proposed numerous physicochemical parameters, but not always the same ones. Until more data are systematically collected with a sufficient number of odorants, the most appropriate physicochemical parameter(s) cannot be determined. At present, vapor pressure seems most reasonable.

\section{REFERENCES}

AMOORE, J. E. Molecular basis of odor. Springfield, Ill: Thomas, 1970.

CAIN, W. S., E ENGEN, T, Olfactory adaptation and the scaling of odor intensity. In C. Pfaffmann (Ed.). intensity. In C. Pfaffmann (Ed): R o cke feller University Press, 1969. Pp. 127-141.

DAVIES, J. T, Recent developments in the "penetration and puncturing" theory of odor. In G. E. W. Wolstenholme and J. Knight (Eds.), Taste and smell in vertebrates. London: Churchill, 1970. Pp. 265-28 1

DöviNG, $K$, Experiments in olfaction In $G, E$. W. Wolstenholme and J. Knight (Eds.), Taste and smell in vertebrates. London: Churchill, 1970. Pp. 197-221.

JONES, F. N. Olfactory absolute thresholds and their implications for the nature of the receptor process. Journal of Psychology, 1955, 40, 223-227.

LAFFORT, $\dot{P}$. Some new data on the physico-chemical determinants of the relative effectiveness of odorants. In $\mathbf{N}$ Tanyolacs (Ed.), Theories of odors and odor measurement. England: Technivision, 1968. Pp 247-268.

MONCRIEFF, R. M. Olfactory adaptation and odor-intensity. American Journal of Psychology, 1957, 70, 1-20.

PRYOR, G, T, STEINMETZ, G., \& STONE, H. Changes in absolute detection thresholds and in subjective intensity of suprathreshold stimuli during olfactory adaptation and recovery. Perception Psychophysics, 1970, 8, 331-335.
STEINMETZ, G., PRYOR, G. T., \& STONE, H, Effect of blank samples on absolute odor threshold determinations. Perception \& Psychophysics, 1969, 3, Perception

STEINMETZ, G., PRYOR, G. T., \& STONE, $\dot{H}$. Oifactory adaptation and recovery in man as measured by two psychophysical techniques. Perception $B$ psychophysical techniques. Percept

STONE, H., OUGH, C. S., \& PANGBORN, R. M. Determination of odor difference thresholds. Journal of Food Science, $1962,27,197-202$

STONE, H., PRYOR, G., \& STEINMETZ, $G$. The design and operation of an improved olfactometer for behavioral and physiological investigation. Behavior Research Methods \& Instrumentation. $1969,1,153-156$.

THEIMER, E. T., \& DAVIES, J. T. Olfaction, musk odor, and molecular properties. Journal of Agriculture \& Food Chemistry, 1967, 15, 6-14.

(Received for publication June 16, 1972; revision received August 14, 1972.) 